\title{
СКРИНИНГОВАЯ ШКАЛА ПОЗИТИВНЫХ И НЕГАТИВНЫХ ПЕРЕЖИВАНИЙ Э. ДИНЕРА: АПРОБАЦИЯ РУССКОЯЗЫЧНОЙ ВЕРСИИ
}

\section{Е.И. РАССКАЗОВА ${ }^{a, b}$, А.А. ЛЕБЕДЕВА}

\author{
${ }^{a}$ Московский государственный университет имени М.В. Ломоносова, 119991, Россия, Москва, \\ Ленинские горы, 1 \\ ${ }^{b}$ Национальный исследовательский университет «Высшая школа экономики», 101000, Россия, \\ Москва, ул. Мясниикая, д. 20
}

\begin{abstract}
Резюме
Развитие позитивной психологии, психологии здоровья и биопсихосоциального подхода к здоровью в медицине сместило акцент в диагностике эмоций в сторону позитивных индикаторов стабильных эмоций в рамках скрининговых инструментов, позволяющих сопоставить выраженность позитивных и негативных эмоций с когнитивной оценкой жизни. В подходе Э. Динера субъективное благополучие определяется через три его взаимосвязанных компонента - удовлетворенность как результат когнитивной оценки своей жизни, позитивные и негативные эмоции как аффективные проявления. Наиболее распространенная в мире шкала психодиагностики эмоций PANAS критикуется Э. Динером ввиду того, что большинство ее пунктов оценивают переживания, связанные с высоким уровнем возбуждения, а не качественные особенности эмоций. В виде альтернативы он предложил шкалу позитивных и негативных переживаний (SPANE), отличающуюся бо́льшим акцентом на модальности в отличие от интенсивности эмоций и краткостью. Целью работы была апробация русскоязычной версии шкалы. 179 студентов психологических специальностей и 100 взрослых респондентов заполняли русскоязычную версию шкалы и шкалу удовлетворенности жизнью. Студенты отвечали также на вопросы краткой версии опросника качества жизни, краткой версии опросника качества жизни и удовлетворенности и методики СОРЕ. Согласно полученным данным, методика характеризуется достаточной надежностьюсогласованностью (альфа Кронбаха $=0.81-0.89)$, ретестовой надежностью $(r=0.52-0.65)$ и факторной валидностью, а ее субшкалы ожидаемым образом коррелируют с удовлетворенностью жизнью, качеством жизни, особенно в сферах переживаний и общения, а также копинг-стратегиями, традиционно относимыми к «продуктивным», что свидетельствует о внешней валидности шкалы. Шкала может использоваться для задач скрининговой диагностики позитивных и негативных эмоций в психологических исследованиях.
\end{abstract}

Ключевые слова: психодиагностика, шкала позитивных и негативных переживаний, концепция субъективного благополучия Э. Динера, удовлетворенность жизнью, качество жизни.

Работа выполнена при поддержке Российского научного фонда, проект № 18-18-00480 «Субъективные индикаторы и психологические предикторы качества жизни». 
Проблема психодиагностики эмоционального состояния человека имеет длительную историю, ее разработку начал К. Изард - он предложил дифференциальную теорию эмоций (см.: Chiccetti, 2015) и соответствующий диагностический инструментарий (см.: Леонова, Капица, 2003). Новый оттенок звучания эта проблема получает, с одной стороны, с развитием биопсихосоциального подхода в медицине и психологии здоровья, делающих акцент на субъективном благополучии и качестве жизни личности как ключевой зависимой переменной в исследованиях (Sarafino, Smith, 2011; Sirgy et al., 2006) и, с другой стороны, с развитием позитивной психологии (Селигман, 2006), описавшей позитивное и негативное эмоциональное состояние личности как две составляющие субъективного благополучия личности (Diener, Ryan, 2009). Как следствие, наибольшую востребованность получили скрининговые инструменты, измеряющие устойчивое эмоциональное состояние ${ }^{1}$, совместимые, сопоставимые и обеспечивающие возможность интеграции с другими методами оценки удовлетворенности и качества жизни. Напротив, на второй план отошли (хотя и не потеряли популярности) методики, уделяющие внимание исключительно негативным индикаторам (тревоге, депрессии и др.).

Наибольшее распространение получила шкала позитивного и негативного аффекта (Positive and Negative Affect Schedule, PANAS), в расширенной версии включающая 60 пунктов (Watson, Clark, 1994), а в сокращенной - 20 (Watson et al., 1988). Пункты представляют собой прилагательные-описания состояний, в полной версии они объединяются не только в группы позитивных и негативных эмоций, но и в специфические подгруппы (радость, уверенность, враждебность и др.). Краткая русскоязычная версия PANAS была апробирована (Осин, 2012) под аббревиатурой ШПАНА (шкала позитивного и негативного аффекта). В отличие от схожей по методическому замыслу использования прилагательных-описаний шкалы дифференциальных эмоций К. Изарда, в которой оценки эмоционального состояния группируются по 10 базовым эмоциям, объединенным в три сводных индекса (позитивных, острых негативных и тревожно-депрессивных эмоций - Леонова, Капица, 2003), в шкале позитивного и негативного аффекта субшкалы отражают лишь знак, а не содержание эмоциональных переживаний.

Широкое распространение методики PANAS отчасти обусловлено ее согласованностью с одной из доминирующих в позитивной психологии моделей субъективного благополучия (Рассказова, 2012б; Ilic et al., 2010) - трехкомпонентным подходом Э. Динера. Подход относится к так называемым концепциям по типу «сверху вниз», с точки зрения которых ситуативное состояние человека зависит от общей склонности к определенному восприятию мира. Хотя внешние факторы меняют благополучие на какое-то время, часто оно относительно быстро возвращается к близкому к исходному уровню (Diener, Ryan, 2009) и в целом стабильно настолько, что порождает вопросы о возможности длительных существенных изменений в уровне благополучия.

\footnotetext{
${ }^{1}$ Обсуждение возможностей диагностики ситуативного эмоционального состояния и его изменчивости требует отдельного обзора и выходит за рамки данной работы.
} 
В подходе Э. Динера субъективное благополучие определяется через три его взаимосвязанных компонента - удовлетворенность как результат когнитивной оценки своей жизни, а также позитивные и негативные эмоции как аффективные проявления. Шкала PANAS удачно «встраивается» в эту модель, позволяя оценить позитивные и негативные эмоции в дополнение к оценке удовлетворенности жизнью, скрининговую шкалу которой предложил Э. Динер (Diener et al., 1985). Шкала удовлетворенности жизнью апробирована в русской версии (Осин, Леонтьев, 2008) и, в отличие от схожих инструментов (например, шкалы субъективного счастья С. Любомирски Lyubomirsky, Lepper, 1999), ориентирована на когнитивную оценку жизни в целом по отношению к некоторому субъективному стандарту или идеалу ( $\mathrm{У}$ меня есть в жизни то, что мне по-настоящему нужно», «В основном моя жизнь близка к идеалу»).

Следует отметить, что Э. Динер и его коллеги выступили с критикой PANAS ввиду того, что большинство ее пунктов оценивают переживания, связанные с высоким уровнем возбуждения (активный, сильный и т.п.), а не качественные особенности эмоций (например, счастливый, благодарный, любящий и т.п.). Э. Динер предложил собственную скрининговую методику для оценки позитивных и негативных эмоций - шкалу позитивных и негативных переживаний (Scale of Positive and negative experience, SPANE - Diener et al., 2010). Методика предложена как альтернатива PANAS, она не только более краткая (12 пунктов), но и более четкая концептуально, а также включающая описания позитивных и негативных переживаний с разным уровнем возбуждения. К настоящему моменту шкала переведена более чем на 10 языков и используется в исследованиях в позитивной психологии (Howel, Buro, 2015; Sabir et al., 2018), в том числе в исследованиях подростков (Singh, Junnarkar, 2015). Хотя шкала и не получила такой же популярности, как SPANE, однако по сравнению со PANAS она позволяет дополнительно предсказать 4-11\% дисперсии в показателях удовлетворенности жизнью, депрессии и общего благополучия у взрослых и 4-17\% - у подростков (Jovanović, 2015).

Целью данного исследования является апробация русскоязычной версии шкалы позитивных и негативных переживаний Э. Динера как скрининговой альтернативы другим шкалам оценки эмоционального состояния. Задачами являлись установление надежности-согласованности, ретестовой надежности, факторной валидности, а также внешней валидности (в отношении шкал качества жизни и благополучия, удовлетворенности жизнью, совладающего поведения).

Для задач валидизации в данной работе использовались те методики оценки качества жизни, которые в своей операционализации этого понятия делают акцент на удовлетворенности и переживаниях в различных сферах (Sirgy et al., 2006; McDowel, 2006). В первую очередь нас интересовала связь с удовлетворенностью эмоциональной сферой и сферой общения. Кроме того, учитывая тесную связь эмоциональных переживаний и субъективной оценки здоровья, ожидалось, что позитивные и негативные переживания будут сопряжены с качеством жизни в сфере здоровья. 


\section{Методы}

В первую группу вошли 179 студентов психологических специальностей (факультета психологии МГУ имени М.В. Ломоносова и МГППУ)², преимущественно женщин (163 женщины, 91.1\%), в возрасте от 17 до 30 лет (средний возраст $-19.27 \pm 2.73$ года). Все респонденты первой группы заполняли Шкалу позитивных и негативных переживаний Э. Динера (SPANE - Diener et al., 2010) - скрининговый инструмент оценки выраженности позитивных и негативных переживаний за последние четыре недели. Методика включает 12 описаний состояния (список представлен в таблице 2), шесть позитивных и шесть негативных, последовательно чередуемых и оцениваемых по шкале Лайкерта от 1 («очень редко или никогда») до 5 («очень часто или постоянно»). По замыслу авторов, прилагательные более нейтральны, чем в шкале PANAS, и в меньшей степени зависят от уровня возбуждения (например, «приятно», «негативно» и др.). Методика была опубликована в открытом доступе и разрешена авторами к использованию в научных целях. На предварительном этапе апробации один из авторов выполнял прямой перевод шкалы, затем содержание каждого пункта и его соответствие англоязычному варианту обсуждались группой из трех кандидатов психологических наук, специализирующихся в области исследования качества жизни и благополучия ${ }^{3}$. Затем выполнялся независимый обратный перевод методики, содержание пунктов соотносилось с оригиналом и вновь корректировалось. Сохранены авторская инструкция и последовательность слов в списке.

Для проверки внешней валидности в исследование были включены шкала удовлетворенности жизнью, тесно связанная, по замыслу Э. Динера, с эмоциональным состоянием, шкалы диагностики качества жизни, позволяющие сопоставить эмоциональное благополучие и удовлетворенность эмоциональными переживаниями с удовлетворенностью другими жизненными сферами, а также методика оценки копинг-стратегий, что обосновано их участием в регуляции эмоционального состояния (Garnefski et al., 2002). Респонденты заполняли следующие методики:

1. Шкала удовлетворенности жизнью Э. Динера (SWLS - Diener et al., 1985; Осин, Леонтьев, 2008) - скрининговый инструмент оценки удовлетворенности жизнью как когнитивной составляющей психологического благополучия. Включает 5 пунктов, оцениваемых по шкале Лайкерта от 1 до 7.

2. Краткая версия опросника качества жизни BO3 WHOQOL-BREF (Skevington et al., 2004; Бурковский и др., 1995) соответствует представлению о качестве жизни как реализующемся в различных жизненных сферах-доменах и включает 26 пунктов, оцениваемых по шкале Лайкерта от 1 до 5. Пункты опросника описывают преимущественно субъективную удовлетворенность различными аспектами жизни или их достаточность для нужд человека; однако они

\footnotetext{
${ }^{2}$ Авторы благодарны проф. А.Н. Кричевцу и проф. С.Н. Ениколопову за помощь в организации сбора данных.

${ }^{3}$ Помимо авторов, в группу входил Е.Н. Осин. Авторы благодарят его за консультацию.
} 
включают и прямую оценку здоровья, жизни, ее наполненности смыслом и т.п. (см.: Рассказова, 2012б). Оценивает качество жизни в четырех сферах физическое здоровье, психологическое здоровье, социальные отношения и окружающая среда.

3. Опросник качества жизни и удовлетворенности - краткая версия (Q-Les-Q - Ritsner et al., 2005; Рассказова, 2012a) предложен в качестве сокращенной версии опросника качества жизни и удовлетворенности (Endicott et al., 1993) - шкалы, разработанной для оценки субъективного уровня удовольствия и удовлетворенности в разных сферах жизни. Данная версия получила максимальное распространение в клинической практике, поскольку в ней выделены сферы, особенно важные для лиц с психическими заболеваниями ${ }^{4}$. Включает 17 основных и 6 дополнительных вопросов, оцениваемых по шкале Лайкерта от 1 до 5 и объединяемых в четыре шкалы - качество жизни и удовлетворенность в сферах здоровья, эмоций, активности в свободное время и общения.

4. Методика диагностики совладающего поведения COPE (Carver et al., 1989; Рассказова и др., 2013) включает 60 пунктов, оцениваемых по шкале Лайкерта от 1 до 4 баллов, и направлена на оценку выраженности 15 общих копинг-стратегий: 1) активное совладание, 2) планирование, 3) подавление конкурирующей деятельности, 4) сдерживание совладания, 5) поиск инструментальной социальной поддержки, 6) поиск эмоциональной социальной поддержки, 7) концентрация на эмоциях, 8) позитивное переформулирование, 9) отрицание, 10) принятие, 11) обращение к религии, 12) использование «успокоительных» (алкоголя, успокоительных средств, лекарств), 13) юмор, 14) поведенческий уход от проблемы и 15) мысленный уход от проблемы. Копинг-стратегии оценивались в данном исследовании в связи с их участием в регуляции эмоционального состояния (Garnefski et al., 2002). В соответствии с этими данными предполагалось, что копинг-стратегии, традиционно относимые к «эмоционально-ориентированным», но сопряженные с избеганием или, напротив, концентрацией на эмоциях (концентрация на эмоциях, уход от проблемы, использование «успокоительных», отрицание), будут связаны с более выраженными негативными переживаниями, а сопряженные с активным, в том числе когнитивным, преобразованием ситуации и своего состояния (юмор, позитивное переформулирование, планирование, активное совладание), а также поиском поддержки - с позитивными эмоциями.

Через 2.5 месяца после проведения исследования 128 человек исходной выборки заполнили шкалу позитивных и негативных переживаний повторно для оценки ретестовой надежности. Интервал в 2.5 месяца был выбран как достаточно длительный, в сравнении с 4 неделями, по которым происходит оценка в инструкции методики, чтобы позволить продемонстрировать устойчивость инструмента, измеряющего устойчивое эмоциональное состояние (по

\footnotetext{
${ }^{4}$ Включение методики в данное исследование обусловлено наличием русскоязычной апробированной версии, психометрические показатели которой позволяют применять ее в исследованиях в норме.
} 
Э. Динеру, хотя все составляющие благополучия подвержены ситуативным колебаниям, относительно устойчивы в продолжительной перспективе) с течением времени.

Во вторую группу вошло 100 взрослых жителей г. Москвы и Московской области (38 мужчин и 62 женщины) в возрасте от 21 года до 68 лет (средний возраст $-30.03 \pm 10.71$ года). Из них у 14 человек (14\%) было среднее или среднее специальное образование, у 23 (23\%) - неоконченное высшее и 61 (61\%) высшее образование; двое образование не указали. Респонденты этой группы заполняли только шкалы позитивных и негативных переживаний и удовлетворенности жизнью Э. Динера. Респонденты рекрутировались следующим образом: в рамках одного из учебных курсов студентов просили предложить знакомым взрослым людям без психических или тяжелых соматических заболеваний старше 20 лет и моложе 70 лет принять участие в исследовании психологического благополучия. Выразившие интерес заполняли методики в рамках очной встречи с исследователем.

\section{Результаты}

Как показано в таблице 1, субшкалы позитивных и негативных эмоций характеризовались достаточной надежностью-согласованностью и тест-ретестовой надежностью через 2.5 месяца. Корреляция субшкал позитивных и негативных эмоций составляет $r=-0.58(p<0.01)$ в группе студентов и $r=-0.38(p<0.01)$ в группе взрослых респондентов. Не выявлено изменений в уровне позитивных и негативных эмоций за 2.5 месяца $(t=-0.18$ и $t=-0.83$, $p>0.40)$.

По данным второй группы, выраженность позитивных и негативных эмоций не была связана с возрастом респондентов $(r=-0.16$ для позитивных эмоций и $r=-0.05$ для негативных эмоций, $p>0.05)$ и не различалась у мужчин и женщин $(t=0.67$ для позитивных эмоций и $t=-1.34$ для негативных эмоций, $p>0.05)$.

Таблица 1

Альфа Кронбаха, тест-ретестовые корреляции и описательная статистика по субшкалам шкалы

\begin{tabular}{|c|c|c|c|c|c|c|c|}
\hline \multirow{2}{*}{ Субшкалы } & \multicolumn{3}{|c|}{ Студенты (N = 179) } & \multirow{2}{*}{$\begin{array}{c}\text { Тест- } \\
\text { ретест } r \\
(\mathrm{~N}=128)\end{array}$} & \multicolumn{3}{|c|}{$\begin{array}{c}\text { Взрослые респонденты } \\
\text { (N = 100) }\end{array}$} \\
\hline & $\begin{array}{c}\text { Альфа } \\
\text { Кронбаха }\end{array}$ & Среднее & Ст. откл. & & $\begin{array}{l}\text { Альфа } \\
\text { Кронбаха }\end{array}$ & Среднее & Ст. откл. \\
\hline $\begin{array}{l}\text { Позитивные } \\
\text { эмоции }\end{array}$ & 0.89 & 3.58 & 0.74 & $0.62 * *$ & 0.81 & 3.77 & 0.65 \\
\hline $\begin{array}{l}\text { Негативные } \\
\text { эмоции }\end{array}$ & 0.85 & 2.65 & 0.80 & $0.55^{* *}$ & 0.82 & 2.55 & 0.79 \\
\hline
\end{tabular}

** $p<0.01$. 
Факторный анализ пунктов шкалы позитивных и негативных переживаний в группах студентов и взрослых респондентов

\begin{tabular}{|c|c|c|c|c|}
\hline \multirow{2}{*}{$\begin{array}{l}\text { Пункты шкалы } \\
\text { («Как часто вы } \\
\text { чувствовали себя } \\
\text { за последние че- } \\
\text { тыре недели...») }\end{array}$} & \multicolumn{2}{|c|}{ Студенты ( $\mathrm{N}=179)$} & \multicolumn{2}{|c|}{ Взрослые респонденты ( $\mathrm{N}=100)$} \\
\hline & $\begin{array}{c}\text { Фактор 1: } \\
\text { Позитивные } \\
\text { эмоции }\end{array}$ & $\begin{array}{c}\text { Фактор 2: } \\
\text { Негативные } \\
\text { эмоции }\end{array}$ & $\begin{array}{c}\text { Фактор 1: } \\
\text { Позитивные } \\
\text { эмоции }\end{array}$ & $\begin{array}{c}\text { Фактор 2: } \\
\text { Негативные } \\
\text { эмоции }\end{array}$ \\
\hline Позитивно & 0.73 & -0.32 & 0.77 & -0.22 \\
\hline Негативно & -0.45 & 0.75 & -0.12 & 0.86 \\
\hline Хорошо & 0.73 & -0.26 & 0.70 & -0.28 \\
\hline Плохо & -0.32 & 0.79 & -0.13 & 0.85 \\
\hline Приятно & 0.75 & -0.05 & 0.70 & -0.17 \\
\hline Неприятно & -0.29 & 0.74 & -0.14 & 0.77 \\
\hline Счастливым & 0.85 & -0.17 & 0.68 & -0.23 \\
\hline Расстроенным & -0.22 & 0.80 & -0.24 & 0.83 \\
\hline Напуганным & 0.07 & 0.54 & -0.14 & 0.46 \\
\hline Радостным & 0.81 & -0.22 & 0.76 & -0.02 \\
\hline Раздраженным & -0.28 & 0.62 & -0.04 & 0.46 \\
\hline Довольным & 0.75 & -0.32 & 0.69 & 0.00 \\
\hline $\begin{array}{l}\text { Собственные } \\
\text { значения }\end{array}$ & 4.11 & 3.38 & 2.31 & 5.20 \\
\hline $\begin{array}{l}\text { Процент } \\
\text { объясняемой } \\
\text { дисперсии }\end{array}$ & 34.28 & 28.12 & 19.26 & 43.32 \\
\hline
\end{tabular}

Факторный анализ (с вращением Varimax) по результатам обеих групп позволяет выявить две компоненты, полностью соответствующие факторам позитивных и негативных эмоций и объясняющие $62.46 \%$ дисперсии данных в выборке студентов и $62.58 \%$ в выборке взрослых респондентов (таблица 2).

И позитивные, и негативные эмоции связаны с удовлетворенностью жизнью (в обеих группах, таблица 3) и всеми шкалами качества жизни и удовлетворенности. Наиболее тесные связи отмечаются с психологическим здоровьем по WHOQOL-BREF и удовлетворенностью в сферах эмоций и общения. В остальных сферах корреляции несколько ниже, однако остаются высокими по модулю.

Иная картина отмечается в отношении копинг-стратегий. Стратегии, традиционно рассматривающиеся как наиболее «продуктивные», - позитивное переформулирование, активное совладание, юмор, в меньшей степени планирование - связаны как с позитивными (положительно), так и с негативными (отрицательно) эмоциями. Напротив, копинги, описывающие поведенческий 
Корреляции субшкал позитивных и негативных эмоций с методиками оценки удовлетворенности, качества жизни и копинг-стратегий

\begin{tabular}{|c|c|c|}
\hline $\begin{array}{c}\text { Методики оценки удовлетворенности, качества } \\
\text { жизни и копинг-стратегий }\end{array}$ & $\begin{array}{l}\text { Позитивные } \\
\text { эмоции }\end{array}$ & $\begin{array}{l}\text { Негативные } \\
\text { эмоции }\end{array}$ \\
\hline SWLS - Удовлетворенность жизнью & $0.47 * / 0.44^{* *}$ & $-0.32 * * /-0.42 * *$ \\
\hline WHOQOL - Физическое здоровье & $0.54^{* *}$ & $-0.57^{* *}$ \\
\hline WHOQOL - Психологическое здоровье & $0.70^{* *}$ & $-0.63 * *$ \\
\hline WHOQOL - Социальные отношения & $0.50 * *$ & $-0.49 * *$ \\
\hline WHOQOL - Окружающая среда & $0.48 * *$ & $-0.35^{* *}$ \\
\hline $\begin{array}{l}\text { Q-Les-Q - Качество жизни и удовлетворенность в } \\
\text { сфере здоровья }\end{array}$ & $0.41 * *$ & $-0.41^{* *}$ \\
\hline $\begin{array}{l}\text { Q-Les-Q - Качество жизни и удовлетворенность в } \\
\text { сфере эмоций }\end{array}$ & $0.72^{* *}$ & $-0.48^{* *}$ \\
\hline $\begin{array}{l}\text { Q-Les-Q - Качество жизни и удовлетворенность в } \\
\text { сфере активности в свободное время }\end{array}$ & $0.30 * *$ & $-0.27^{* *}$ \\
\hline $\begin{array}{l}\text { Q-Les-Q - Качество жизни и удовлетворенность в } \\
\text { сфере общения }\end{array}$ & $0.56^{* *}$ & $-0.30^{* *}$ \\
\hline $\begin{array}{l}\text { СОРЕ - Позитивное переформулирование и } \\
\text { личностный рост }\end{array}$ & $0.32^{* *}$ & $-0.27^{* *}$ \\
\hline СОРЕ - Мысленный уход от проблемы & -0.12 & 0.12 \\
\hline $\begin{array}{l}\text { СОРЕ - Концентрация на эмоциях и их активное } \\
\text { выражение }\end{array}$ & -0.15 & $0.30^{* *}$ \\
\hline $\begin{array}{l}\text { СОРЕ - Использование инструментальной } \\
\text { социальной поддержки }\end{array}$ & $0.19^{*}$ & 0.01 \\
\hline СОРЕ - Активное совладание & $0.21 * *$ & $-0.20 * *$ \\
\hline СОРЕ - Отрицание & 0.01 & 0.10 \\
\hline СОРЕ - Обращение к религии & 0.01 & 0.07 \\
\hline СОРЕ - Юмор & $0.21 * *$ & $-0.18^{*}$ \\
\hline СОРЕ - Поведенческий уход от проблемы & $-0.19^{*}$ & $0.20^{* *}$ \\
\hline СОРЕ - Сдерживание & 0.01 & 0.01 \\
\hline $\begin{array}{l}\text { СОРЕ - Использование эмоциональной } \\
\text { социальной поддержки }\end{array}$ & $0.22^{* *}$ & -0.02 \\
\hline СОРЕ - Использование «успокоительных» & $-0.17^{*}$ & $0.28 * *$ \\
\hline СОРЕ - Принятие & 0.01 & 0.07 \\
\hline СОРЕ - Подавление конкурирующей деятельности & 0.07 & -0.01 \\
\hline СОРЕ - Планирование & $0.18^{*}$ & $-0.16^{*}$ \\
\hline
\end{tabular}

${ }^{*} p<0.05,{ }^{* *} p<0.01$. 
уход или использование «успокоительных», связаны с высоким уровнем отрицательных и низким уровнем положительных переживаний. Интересно, что речь идет именно о поведенческих копингах, тогда как более когнитивные варианты, такие как мысленный уход от проблемы, отрицание или сдерживание, с эмоциями не связаны. Не связаны с эмоциями также и принятие, обращение к религии и подавление конкурирующей деятельности.

Стратегии, связанные с поиском социальной поддержки (как эмоциональной, так и инструментальной, хотя и в меньшей степени) связаны с более высоким уровнем позитивных, но не с негативными эмоциями; тогда как концентрация на эмоциях и их выражении, напротив, сопряжена с отрицательными, но не с положительными переживаниями.

\section{Обсуждение результатов}

Итак, полученные результаты свидетельствуют о высокой надежностисогласованности и факторной валидности шкалы SPANE. В соответствии с концепциями по типу «сверху вниз» как позитивные, так и негативные эмоции оказались достаточно устойчивыми с течением времени, а их связь между собой, хотя и относительно высокая, не столь высока (в первую очередь, в выборке взрослых), чтобы считать их разными сторонами одного континуума. Тот результат, что уровень позитивных и негативных эмоций практически не связан с полом и возрастом респондентов, на наш взгляд, также согласуется с представлением, что речь идет об общей оценке стабильных особенностей личности (общей выраженности эмоций). Следует, однако, отметить, что поскольку в студенческой выборке большинство респондентов были женского пола, этот результат основан исключительно на анализе второй выборки и требует воспроизведения в дальнейших исследованиях. При этом данные в пользу стабильности результатов SPANE не дают возможности применять методику для оценки ситуативных изменений или колебаний в эмоциональном состоянии, для задачи оценки динамики должны использоваться другие инструменты.

Внешняя валидность шкалы подтверждается результатами корреляционного анализа: тесной связью позитивных и негативных эмоций как с другими аспектами психологического благополучия (удовлетворенностью), так и более тесной их связью с психологическим здоровьем и качеством жизни в сферах эмоций и общения, нежели в других сферах. В соответствии с существующими данными о субъективной оценке здоровья позитивные переживания связаны с более высоким качеством жизни в этой сфере и оценкой своего физического здоровья, а негативные - с более низким. Интересно, что наиболее слабы связи эмоций с удовлетворенностью активностью в свободное время. Задачей дальнейших исследований может быть установление, является ли этот феномен специфичным для студентов (т.е. их деятельность в свободное время не столь важна для их переживаний, как, например, общение) или общим.

К сожалению, в рамках данной работы проверка конвергентной валидности SPANE проводилась лишь в сопоставлении со шкалами психологического 
здоровья и удовлетворенности эмоциональными переживаниями. Не было проведено прямого сопоставления SPANE и PANAS, в первую очередь, в отношении их предсказательной способности, что, безусловно, является задачей проспективных исследований.

В соответствии с представлениями о копинг-стратегиях как стратегиях регуляции, в том числе эмоционального состояния (Garnefski et al., 2002), копинг-стратегии, связанные с избеганием (поведенческий уход от проблемы, использование «успокоительных») и концентрацией на эмоциях, коррелируют, в первую очередь, с выраженностью негативных эмоций, а копинг-стратегии, ориентированные на поиск поддержки, - с позитивными эмоциями. Следует отметить, что склонность ни к отрицанию, ни к мысленному уходу от проблемы не была связана с эмоциональными переживаниями. Хотя эти результаты требуют уточнения, можно предполагать, что в отличие от ситуативного избегания (поведенческого или по типу приема «успокоительных» средств) отрицание является более продуктивной психической защитой, дающей эмоциональное облегчение в сложной ситуации. Шкала мысленного ухода характеризуется невысокой согласованностью (Рассказова и др., 2013), что может объяснять полученные результаты. Интересно, что стратегии, направленные на активное преобразование своего состояния и ситуации (юмор, позитивное переформулирование, планирование, активное совладание), практически в равной мере связаны и с более высоким уровнем позитивных эмоций, и с более низким уровнем негативных. Не противореча исходной гипотезе о внешней валидности методики, эти данные указывают, что копингстратегии, традиционно рассматриваемые как «продуктивные», связаны с общим более благополучным эмоциональным фоном. Этот результат в целом был ожидаемым: с одной стороны, позитивное переформулирование и юмор (и в меньшей степени планирование) требуют хорошего учета контекста, целостной картины, что является одной из центральных функций позитивных эмоций (Fredrickson, 2001). С другой стороны, чрезмерно узкая перспектива, характерная для «черно-белого» мышления, сопряжена с негативным эмоциональным фоном. На этом фоне закономерна легкость выбора стратегий совладания, способствующих немедленному облегчению ценой долгосрочных негативных последствий (выбор «успокоительных», поведенческий уход от проблемы).

В целом методика характеризуется достаточной надежностью-согласованностью, ретестовой надежностью и факторной валидностью, а ее шкалы ожидаемым образом коррелируют с удовлетворенностью жизнью, качеством жизни, особенно в сферах переживаний и общения, а также с копинг-стратегиями, традиционно относимыми к «продуктивным». Иными словами, можно говорить о внешней валидности шкалы. Преимуществом инструмента является большая краткость в сравнении с PANAS и ее русскоязычным аналогом (ШПАНА), шкалой К. Изарда, а также акцент на модальности в отличие от интенсивности переживаний. Задачей дальнейших исследований является прямое сопоставление методики, в том числе ее предсказательной способности, с другими инструментами диагностики эмоционального состояния. 


\section{Литература}

Бурковский, Г. В., Коцюбинский, А. П., Левченко, Е. В., Ломаченков, А. С. (1995). Создание русской версии инструмента Всемирной организации здравоохранения для измерения качества жизни. В кн. Проблемы оптимизации образа жизни и здоровья человека (с. 27-28). СПб.

Леонова, А. Б., Капица, М. С. (2003). Методы субъективной оценки функционального состояния человека. В кн. Ю. К. Стрелков (ред.), Практикум по инженерной психологии и эргономике (с. 136167). М.: Издательский центр «Академия».

Осин, Е. Н. (2012). Измерение позитивных и негативных эмоций: разработка русскоязычного аналога методики PANAS. Психология. Журнал Высшей школь экономики, 9(4), 91-110.

Осин, Е. Н., Леонтьев, Д. А. (2008). Апробация русскоязычных версий двух шкал экспресс-оценки субъективного благополучия. В кн. Материаль III Всероссийского социологического конгресса. M.: Ин-т социологии РАН/Российское общество социологов. Режим доступа: https://publications.hse.ru/mirror/pubs/share/folder/pjuun7fz60/direct/78753837

Рассказова, Е. И. (2012, а). Методика оценки качества жизни и удовлетворенности: психометрические характеристики русскоязычной версии. Психология. Журнал Высшей школь экономики, 9(4), 81-90.

Рассказова, Е. И. (2012, б). Методы диагностики качества жизни в науках о человеке. Вестник Московского университета. Серия 14. Психология, 3, 95-107.

Рассказова, Е. И., Гордеева, Т. О., Осин, Е. Н. (2013). Копинг-стратегии в структуре деятельности и саморегуляции: психометрические характеристики и возможности применения методики СОРЕ. Психология. Журнал Высшей школь экономики, 10(1), 82-118.

Селигман, М. (2006). Новая позитивная психология. М.: София.

Ссылки на зарубежные источники см. в разделе References после англоязычного блока.

Рассказова Елена Игоревна - доцент, кафедра нейро- и патопсихологии, факультет психологии МГУ имени М.В. Ломоносова; ведущий научный сотрудник, Международная лаборатория позитивной психологии личности и мотивации, Национальный исследовательский университет «Высшая школа экономики», кандидат психологических наук. Сфера научных интересов: саморегуляция; психология здоровья; позитивная психология; клиническая психология.

Контакты: e.i.rasskazova@gmail.com

Лебедева Анна Александровна - старший научный сотрудник, Международная лаборатория позитивной психологии личности и мотивации, Национальный исследовательский университет «Высшая школа экономики», кандидат психологических наук.

Сфера научных интересов: качество жизни, благополучие, психология здоровья.

Контакты: anna.alex.lebedeva@gmail.com 


\title{
Screening Scale of Positive and Negative Experience (SPANE): Validation of the Russian Version
}

\author{
E.I. Rasskazova ${ }^{\mathrm{a}, \mathrm{b}}$, A.A. Lebedeva ${ }^{\mathrm{b}}$ \\ ${ }^{a}$ Lomonosov Moscow State University, 1 Leninskie Gory, Moscow, 119991, Russian Federation \\ ${ }^{b}$ National Research University Higher School of Economics, 20 Myasnitskaya Str., Moscow, 101000, \\ Russian Federation
}

\begin{abstract}
The development of positive psychology, health psychology and biopsychosocial approach to health in medicine shifted the emphasis in the diagnostics of emotions towards positive indicators of stable emotions in the framework of screening tools, allowing to compare positive and negative emotions with a cognitive appraisal of life. In E. Diener's model, subjective well-being is determined through its three interconnected components - satisfaction as a result of cognitive appraisal of one's life, as well as positive and negative emotions as affective ccomponents. He criticizes the most widespread in the world scale for psycho-diagnostics of emotions PANAS for its emphasize on emotions with a high level of excitation, rather than qualitative features of emotions. As an alternative, he proposed a Scale of Positive and Negative Experiences (SPANE), characterized by a greater emphasis on modality, in contrast to intensity, of emotions. The aim was to validate the Russian version of the scale. 179 students of psychological specialties and 100 adult respondents filled out this scale and Satisfaction with Life Scale. The students also answered the questions of a brief version of WHOQOL and a brief version of the Quality of Life and Satisfaction Questionnaire. According to the data obtained, the scale is characterized by sufficient reliability-consistency (Cronbach alpha 0,81-0,89), test-retest reliability $(\mathrm{r}=0,52-0,65)$ and factor validity. Its subscales correlate with satisfaction with life, quality of life, especially in the domains of emotions and communication, as well as coping strategies that are traditionally described as "productive", which indicates the external validity of the scale. The scale can be used for screening diagnostics of positive and negative emotions in psychological research.
\end{abstract}

Keywords: psychodiagnostics, Scale of positive and negative experience (SPANE), E. Diener's subjective well-being model, satisfaction with life, quality of life.

\section{References}

Burkovskii, G. V., Kotsyubinskii, A. P., Levchenko, E. V., \& Lomachenkov, A. S. (1995). Sozdanie russkoi versii instrumenta Vsemirnoi organizatsii zdravookhraneniya dlya izmereniya kachestva zhizni [Development of the Russian version of the World Health Organization quality of life measure]. In Problemy optimizatsii obraza zhizni i zdorov'ya cheloveka [Issues of optimization of human lifestyle and health] (pp. 27-28). Saint Petersburg. (in Russian)

Study is supported by the Russian Science Foundation, project 18-18-00480 "Subjective indicators and psychological predictors of quality of life". 
Carver, C. S., Scheier, M. F., \& Weintraub, J. K. (1989). Assessing coping strategies: A theoretically based approach. Journal of Personality and Social Psychology, 56(2), 267-283.

Diener, E., Emmons, R. A., Larsen, R. J., \& Griffin, S. (1985). The Satisfaction with Life Scale.Journal of Personality Assessment, 49, 71-75.

Diener, E., \& Ryan, K. (2009). Subjective well-being: a general overview. South African Journal of Psychology, 39, 391-406.

Diener, E., Wirtz, D., Tov, W., Kim-Prieto, C., Choi, D., Oishi, S., \& Bisqas-Diener, R. (2010). New well-being measures: short scales to assess flourishing and positive and negative feelings. Social Indicators Research, 97, 143-156.

Endicott, J., Nee, J., Harrison, W., \& Blumenthal, R. (1993). Psychopharmacology Bulletin, 29(2), 321-326.

Fredrickson, B. L. (2001). The role of positive emotions in positive psychology. American Psychologist, 56(3), 218-226. doi:10.1037/0003-066X.56.3.218

Garnefski, N., Kraaij, V., \& Spinhoven, P. (2002). Manual for the use of the Cognitive Emotion Regulation Questionnaire. Leiderdorf: DATEK.

Howel, A., \& Buro, K. (2015). Measuring and predicting student well-being: Further evidence in support of the Flourishing Scale and the Scale of Positive and Negative Experiences. Social Indicators Research, 121(3), 903-915.

Ilic, I., Milic, I., \& Arandelovic, M. (2010). Assessment quality of life: current approaches. Acta Medica Medianae, 49(4), 52-60.

Jovanović, V. (2015). Beyond the PANAS: incremental validity of the Scale of positive and negative experience (SPANE) in relation to well-being. Personality and Individual Differences, 86, 487-491.

Leonova, A. B., \& Kapitsa, M. S. (2003). Metody sub"ektivnoi otsenki funktsional'nogo sostoyaniya cheloveka [Methods of subjective evaluation of human functional state]. In Yu. K. Strelkov (Ed.), Praktikum po inzhenernoi psikhologii i ergonomike [Practical course in engineering psychology and ergonomics] (pp. 136-167). Moscow: Publishing center "Academy”. (in Russian)

Lyubomirsky, S., \& Lepper, H. (1999). A measure of subjective happiness: preliminary reliability and construct validation. Social Indicators Research, 46, 137-155.

McDowel, J. (2006). Measuring health. A guide to rating scales and questionnaires. New York: Oxford University Press.

Osin, E. N. (2012). Measuring positive and negative affect: Development of a Russian-language analogue of PANAS. Psychology. Journal of Higher School of Economics, 9(4), 91-110. (in Russian)

Osin, E. N., \& Leontiev, D. A. (2008). Aprobatsiya russkoyazychnykh versij dvukh shkal ehkspressotsenkisub'ektivnogo blagopoluchiya [Testing of Russian versions of the two scales of a rapid assessment of subjective well-being]. In Materialy III Vserossijskogo sotsiologicheskogo kongressa [Proceedings of the 3rd National Russian Sociological Congress]. Moscow: Institute of Sociology of the RAS/Rossiiskoe obshchestvo sotsiologov. Retrieved from https://publications.hse.ru/mirror/pubs/share/folder/pjuun7fz60/direct/78753837 (in Russian)

Rasskazova, E. I. (2012, a). Evaluation of quality of life enjoyment and satisfaction: Psychometric properties of a Russian-language measure. Psychology. Journal of Higher School of Economics, 9(4), 81-90. (in Russian)

Rasskazova, E. I. (2012, b). Methods for the quality of life diagnostics in the human sciences. Moscow University Psychology Bulletin. Series 14. Psychology, 3, 95-107. (in Russian)

Rasskazova, E. I., Gordeeva, T. O., \& Osin, E. N. (2013). Coping strategies in the structure of activity and self-regulation: Psychometric properties and applications of the COPE Inventory. Psychology. Journal of Higher School of Economics, 10(1), 82-118. (in Russian) 
Ritsner, M., Kurs, R., Gibel, A., Ratner, Y., \& Endicott, J. (2005). Validity of an abbreviated Quality of life enjoyment and satisfaction questionnaire (Q-LES-Q-18) for schizophrenia, schizoaffective, and mood disorder patients. Quality of Life Research, 14, 1693-1703.

Sabir, F., Ramzan, N., Malik, F. (2018). Resilience, self-compassion, mindfulness and emotional wellbeing of doctors. Indian Journal of Positive Psychology, 9(1), 55-59.

Sarafino, E. P., \& Smith, T. W. (2011). Health psychology: biopsychosocial interactions (7th ed.). New York: Wiley.

Seligman, M. (2006). Novaya pozitivnaya psikhologiya [New positive psychology]. Moscow: Sofiya. (in Russian; transl. of: Seligman, M. (2002). Authentic happiness: Using the new positive psychology to realize your potential for lasting fulfillment. New York: Free Press.)

Singh, K., \& Junnarkar, M. (2015). Correlates and predictors of positive mental health for school going children. Personality and Individual Differences, 76, 82-87.

Sirgy, M. J., Michalos, A. C., Ferris, A. L., Easterlin, R. A., Patrick, D., \& Pavot, W. (2006). The quality of life (QOL) research movement: past, present and future. Social Indicators Research, 76, 343-466.

Skevington, S. M., Lotfy, M., \& O'Connell, K. A. (2004). The World Health Organization's WHOQOL-BREF quality of life assessment: psychometric properties and results of the international field trial. A report from the WHOQOL Group. Quality of Life Research, 13(2), 299-310.

Watson, D., \& Clark, L. A. (1994). The PANAS-X: Manual for the positive and negative affect schedule - expanded form. Iowa City, IA: University of Iowa.

Watson, D., Clark, L. A., \& Tellegen, A. (1988). Development and validation of brief measures of positive and negative affect: the PANAS scales. Journal of Personality and Social Psychology, 54, 1063-1070.

Elena I. Rasskazova - Associate Professor, Department of neuro-and pathopsychology, faculty of psychology, Lomonosov Moscow State University; Lead Research Fellow, International Laboratory of Positive Psychology of Personality and Motivation, Higher School of Economics, $\mathrm{PhD}$ in Psychology.

Research Area: self-regulation, health psychology, positive psychology, clinical psychology.

E-mail: e.i.rasskazova@gmail.com

Anna A. Lebedeva - PhD in Psychology, Senior Research Fellow, International Laboratory of Positive Psychology of Personality and Motivation, Higher School of Economics, PhD in Psychology.

Research Area: quality of life, well-being, health psychology.

E-mail: anna.alex.lebedeva@gmail.com 